\title{
Efficacies of Stem Cell Therapies for Functional Improvement of the $\beta$ Cell in Patients with Diabetes: A Systematic Review of Controlled Clinical Trials
}

\author{
Gyudeok Hwang ${ }^{1}$, Hyunsuk Jeong ${ }^{2}$, Hae Kyung Yang ${ }^{3}$, Hun-Sung Kim ${ }^{4}$ \\ Hanter Hong ${ }^{1}$, Na Jin Kim ${ }^{5}$, Il-Hoan $\mathrm{Oh}^{6}$, Hyeon Woo Yim ${ }^{2}$ \\ ${ }^{I}$ The Catholic University of Korea, Catholic Medical Center, Seoul, Korea \\ ${ }^{2}$ Department of Preventive Medicine, College of Medicine, The Catholic University of Korea, Seoul, Korea \\ ${ }^{3}$ Cell and Gene Therapy Products Division, National Institute of Food and Drug Safety Evaluation, Ministry of Food and Drug \\ Safety, Cheongju, Korea \\ ${ }^{4}$ Division of Endocrinology and Metabolism, Department of Internal Medicine, Seoul St. Mary's Hospital, College of Medicine, The \\ Catholic University of Korea, Seoul, Korea \\ ${ }^{5}$ Medical Library, The Catholic University of Korea, Seoul, Korea \\ ${ }^{6}$ Catholic High-Performance Cell Therapy Center \& Department of Medical Life Science, College of Medicine, The Catholic University \\ of Korea, Seoul, Korea
}

\begin{abstract}
Background and Objectives: This study was performed to investigate whether stem cell therapy enhances $\beta$ cell function by meta-analysis with proper consideration of variability of outcome measurements in controlled trial of type 1 diabetes mellitus (T1DM) and type 2 diabetes mellitus (T2DM) patients.

Methods: A systematic search was performed from inception to January 2018 in PubMed, EMBASE, and Cochrane databases. $\beta$ cell function was assessed by stimulated C-peptide, fasting C-peptide, normal glycosylated hemoglobin levels (HbAlC), and exogenous insulin dose patterns. The quality of the studies were assessed by both the Cochrane Collaboration's Risk of Bias (ROB) for Randomized controlled trials and the Risk of Bias in Non-randomized Studies of Interventions (ROBINS-I) for non-randomized controlled trials.

Results: From the selected final 15 articles, total of 16 trials were analyzed. There were 6 T1DM trials (total 153 cases) and 10 T2DM trials (total 457 cases). In T2DM patients, the changes in stimulated C-peptide, HbAlc, and exogenous insulin dose versus baseline showed a favorable pattern with a significant heterogeneity in stem cell therapy. In T1DM, there was no significant difference between control group and stem cell therapy group in three indicators except for HbAlc. Most of the studies were rated as having high risk of bias in the quality assessment.

Conclusions: The stem cell therapy for DM patients is not effective in T1DM but seems to be effective in improving the $\beta$ cell function in T2DM. However the observed effect should be interpreted with caution due to the significant heterogeneity and high risk of bias within the studies. Further verification through a rigorously designed study is warranted.
\end{abstract}

Keywords: Diabetes mellitus, C-peptide, $\beta$ cell, Stem cell

Received: September 4, 2018, Revised: January 2, 2019, Accepted: February 11, 2019, Published online: April 30, 2019

Correspondence to Hyeon Woo Yim

Department of Preventive Medicine, College of Medicine, The Catholic University of Korea, 222 Banpo-daero, Seocho-gu, Seoul 06591, Korea Tel: +82-2-2258-7860, Fax: +82-2-532-3820, E-mail: y1693@catholic.ac.kr

(a) This is an open-access article distributed under the terms of the Creative Commons Attribution Non-Commercial License (http://creativecommons.org/licenses/by-nc/4.0/), which permits unrestricted non-commercial use, distribution, and reproduction in any medium, provided the original work is properly cited. Copyright (c) 2019 by the Korean Society for Stem Cell Research 


\section{Introduction}

Type 1 diabetes (T1DM) is a disease in which selective insulin-producing $\beta$-cell destruction occurs due to genetic or sporadic autoimmunity. Attempts have been made to stop destruction of $\beta$-cell function. C-peptide is reduced by approximately 0.1 to $0.2 \mathrm{ng} / \mathrm{ml}$ per year, even when intensive insulin therapy with 3 to 4 insulin injections per day is given (1). In Type 2 Diabetes (T2DM), gradual increase in insulin resistance and temporal insulin secretion increase occurs, eventually leading to $\beta$-cell dysfunction (2). Even intensive therapy using drugs such as metformin and sulfonylurea, including insulin, eventually leads to deterioration of $\beta$-cell function and glycemic control becomes difficult $(3,4)$. In T2DM, the $\beta$-cell function is initially reduced by about $10 \%$ in 10 years, and at some point, it decreases rapidly by about $10 \%$ in 2 years, eventually resulting in insulin-dependent diabetes (5).

Therefore, treatment with stem cells having functions of immune modulation and regeneration has been continuously tried to improve the $\beta$-cell function. There are many types of cell therapy trials for DM such as pancreatic islet cell transplantation, pancreatic ductal stem cells, MSC transplantation or hematopoietic stem cells (or bone marrow transplantation). C-peptide was significantly increased by immunosuppression and immune resetting with administration of hematopoietic stem cells after immune ablation conditioning in type 1 diabetes (6). However, bone marrow transplantation (BMT) can cause many side effects such as graft versus host disease (GVHD), gonad dysfunction, and endocrine dysfunction, as well as infection by immune suppression (7). Also, treatment-related mortality for immune ablation BMT may be present, although less than $1 \%(8)$, Thus BMT is a burden for diabetes patients who have no hematologic malignancy. In T2DM patients, C-peptide was significantly increased by locally injecting bone marrow mononuclear cells via pancreatic artery (9). In T1DM patients, autologous bone marrow stem cells were injected via spleen artery, and increased c-peptide levels were maintained for 3 years. Controlled trials also were conducted to compare the efficacy of stem cell therapies $(10,11)$.

C-peptide, glycated hemoglobin (HbAlc) and required exogenous insulin dose have been used to evaluate the efficacy of stem cell therapy in diabetic patients, and c-peptide is recommended as a surrogate marker for evaluating $\beta$-cell function in insulin-dependent diabetes mellitus (12-14). C-peptide was measured by a fasting sample, a non-fasting random sample, and a formal stimulation test, and there are various kinds of stimulation tests like an intravenous glucagon stimulation (IVGS), a standardized mixed-meal tolerance test (MMTT), and oral glucose tolerance test (OGTT). In the study of stem cell therapy in diabetic patients, C-peptide measurements were measured in various ways.

Three meta-analyses of stem cell therapy in DM patients have been reported (15-17). However, in an analysis of whether stem cell therapy improves $\beta$-cell function, comparative analysis of only controlled studies to avoid overestimation of stem cell therapy effectiveness was not performed. Diversity of c-peptide measurements as an index of $\beta$-cell functional improvement was not considered. And C-peptide, glycated hemoglobin ( $\mathrm{HbAlc}$ ) and the required exogenous insulin dose were not analyzed integrally in the evaluation of $\beta$-cell function improvement.

Therefore, this systematic review aims to investigate whether the injected stem cell therapy promotes $\beta$-cell function, we analyzed controlled trials that evaluated the effect of stem cell treatment on diabetic patients. Diversity of c-peptide measurement method was analyzed and the exogenous insulin dose and HBAlC concentration were considered integratively.

\section{Materials and Methods}

\section{Search strategy and study selection}

A systematic search was performed from inception to January 2018 in PubMed, EMBASE, and Cochrane databases to search stem cell therapy studies applied to DM patients. The search terms such as, 'Diabetes Mellitus', 'Stem cell therapy', and 'Efficacies or Safety' were used. Selection criteria for the relevant study were as follows. (1) Controlled trials. (2) Patients with DM. (3) Including any kind of stem cells. Stem cells derived from the fetal organs were also included without excluding $(11,18)$. (4) Including fasting or stimulated C-peptide data. (5) Without a restriction on language. Abstracts are included if they are in English. The text in Chinese is also included (19) with the help of Chinese expert. Exclusion criteria are as follows. (1) No full text. (2) No control groups without stem cell therapies. (3) Treatments for DM complications. (4) Islet cell or pancreas transplantations. (5) Traditional bone marrow stem cell transplantations. (6) Less than 4 participants. (7) No C-peptide data.

\section{Data extraction}

A total of 2,472 articles were searched initially except for duplication of data. Two independent investigators reviewed titles and abstracts and selected 104 potentially eligible studies. Then full text review was conducted. When 
opinions differ in the selection of articles, divergences were resolved by mutual consultation. Finally, 15 articles were selected (10, 11, 18-30) (Fig. 1).

The extracted items in each document are country of patient enrollment, numbers of patients allocated to stem cell treatment and control groups, route of stem cell administration, MSC cell type, cell origin, injection dose, and follow-up period. The mean, standard deviation, and total sample size were extracted for both treatment and control groups at baseline and the each follow-up points of C-peptide, HbAlc, insulin requirements. In the case standard deviation cannot be obtained (30), the author of this document was contacted by e-mail, and if cannot get the response, data was only used for qualitative synthesis

In a single article, two totally different trials were presented with the respective control group (11), and T1DM and T2DM trials were separated and analyzed as independent trials. The number of patients randomized in each trial or the number of patients assigned at the start of the study were extracted. The term 'end of study follow up point' used in this paper refers to the end of trials or the last follow up point of each document.

\section{Quality assessment}

In the case of the randomized controlled trial (RCT), the quality assessment was conducted with Cochrane Collaboration's tool for assessing risk of bias. In the case of non-randomized controlled trial (NRCT), the Risk of

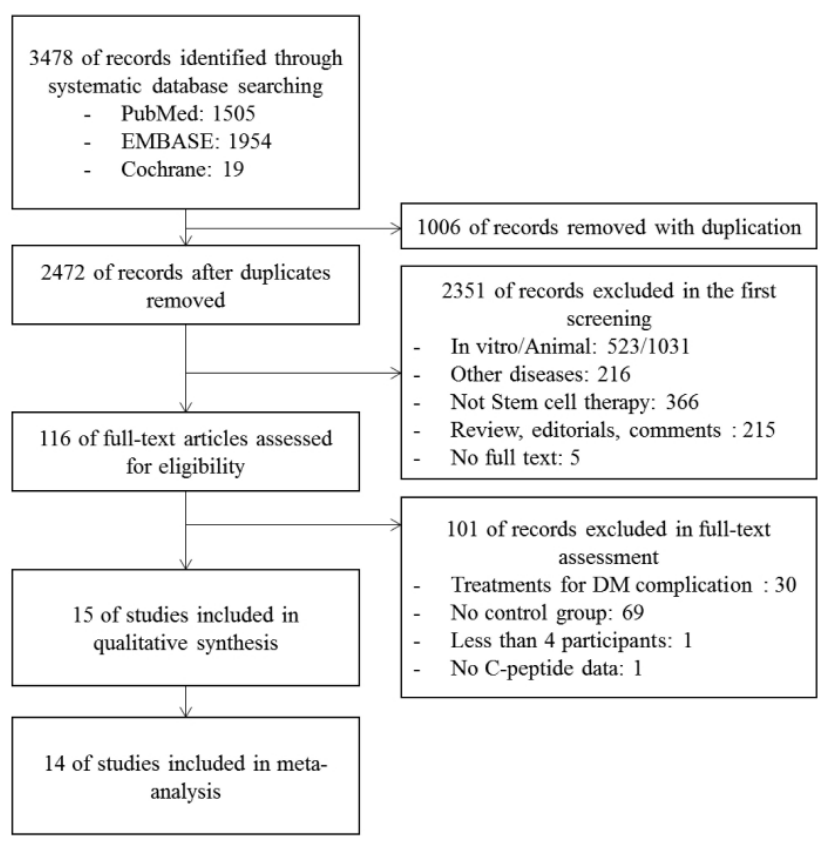

Fig. 1. Flow diagram of studies included in this review.
Bias in Non-randomized Studies of Interventions (ROBINS-I) was used. Two investigators independently performed analysis and divergences were solved through consensus. In RCT, if the control group had the sham procedures such as bone marrow aspiration, catheterization, and saline injection, it was evaluated as a low risk of bias in the blindness domain. In case of selective reporting domain, the registered research protocol was found and compared, and when the protocol was not registered, it was evaluated as unclear. In a case, the registered study protocol was non-randomized 4 factorial design, but was RCT in the reported trial, the study was evaluated based on abstract and full text (19). The confounding elements for NRCTs were age, diabetic duration, and the severity of disease evaluated as a c-peptide baseline level, and if evaluated it was accessed as moderate risk of bias and if even adjustment was performed, it was accessed as low risk of bias. Only the overall risk of bias for each trial was presented as a table (Table 1).

\section{Statistical analyses}

Data analysis was conducted using Review Manager 5.3. C-peptide was converted to ' $\mathrm{ng} / \mathrm{ml}$ ' using the relation (12) of ' $1 \mathrm{nmol} / \mathrm{l}=1 \mathrm{pmol} / \mathrm{ml}=3 \mathrm{ng} / \mathrm{ml}$ '. We used $\%$ as the unit for $\mathrm{HbAlc}$, and for insulin used internal unit (IU). For patients of T1DM, unit for daily required exogenous dose of insulin was $\mathrm{IU} / \mathrm{d} / \mathrm{kg}$, daily dose divided by the body weight of patients, and for T2DM we used unit of IU/d. When data is presented only as a figure, the exact numerical values of the data are extracted from the images using the Web Plot Digitizer Version 3.9 (20, 23, 24, 26, 27). Value of area under the curve (AUC) was selected for the analysis of the stimulated C-peptide. Peak value (28) was used when there was no AUC value. In case standard deviation was not presented, it was calculated from interquartile range, range, standard error values. When there are multiple intervention groups $(10,20-22)$ or multiple control groups (20), they are combined into one group before analysis. In this meta-analysis the random effect model was used, because the type, origin, cell number and the end of study follow up time of stem cell treatment vary in each trial and the possible heterogeneity is suspected. For fasting C-peptide meta-analysis, weighted mean differences were used. For stimulated C-peptide analysis, we used weighted mean differences when AUC was included in the meta-analysis, but the standard mean differences method was used when AUC and peak value were included in the meta-analysis. The $\mathrm{I}^{2}$ statistic was used to evaluate the degree of heterogeneity. We conducted subgroup and meta-regression analyses to explore methodo- 


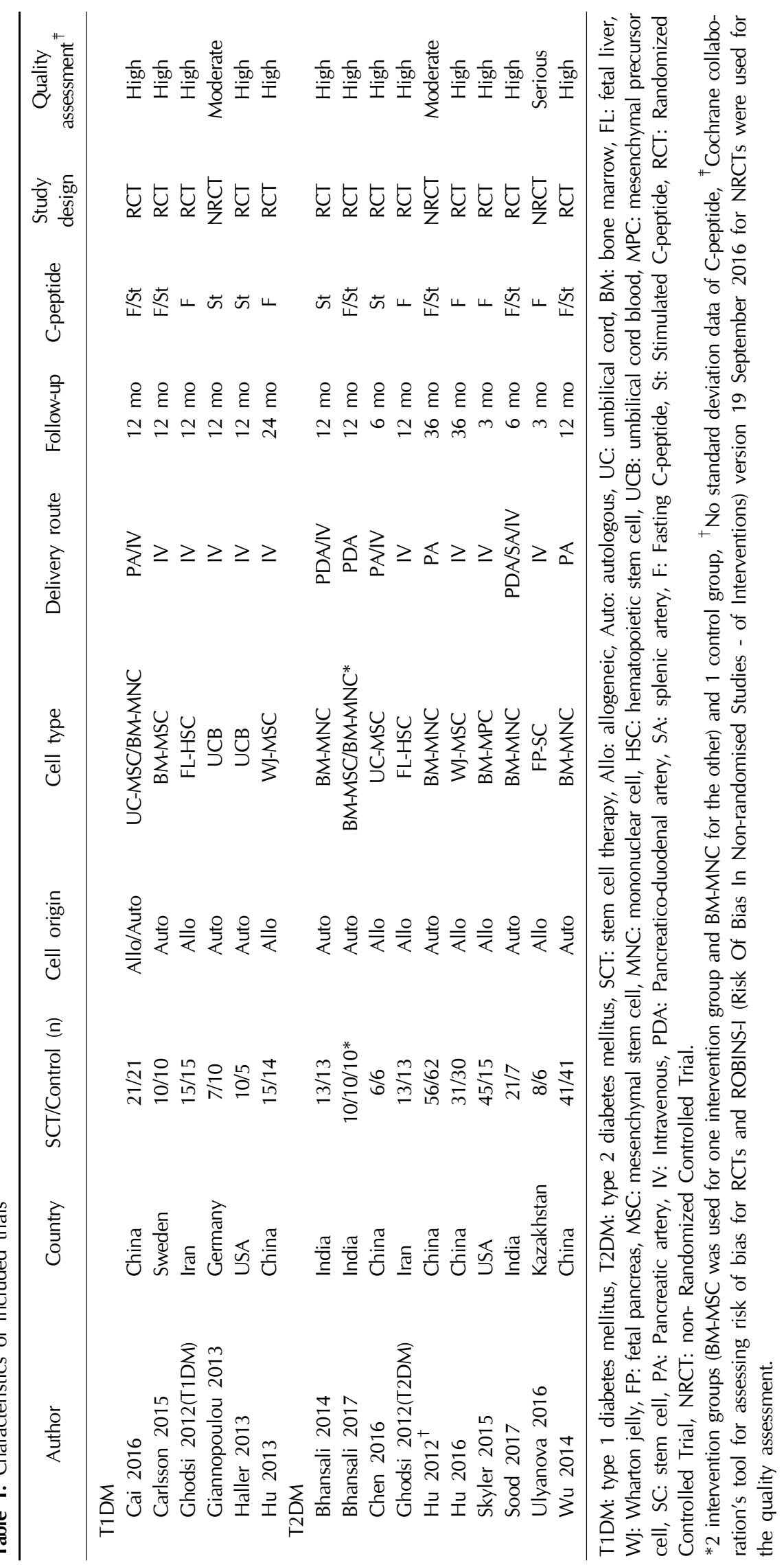




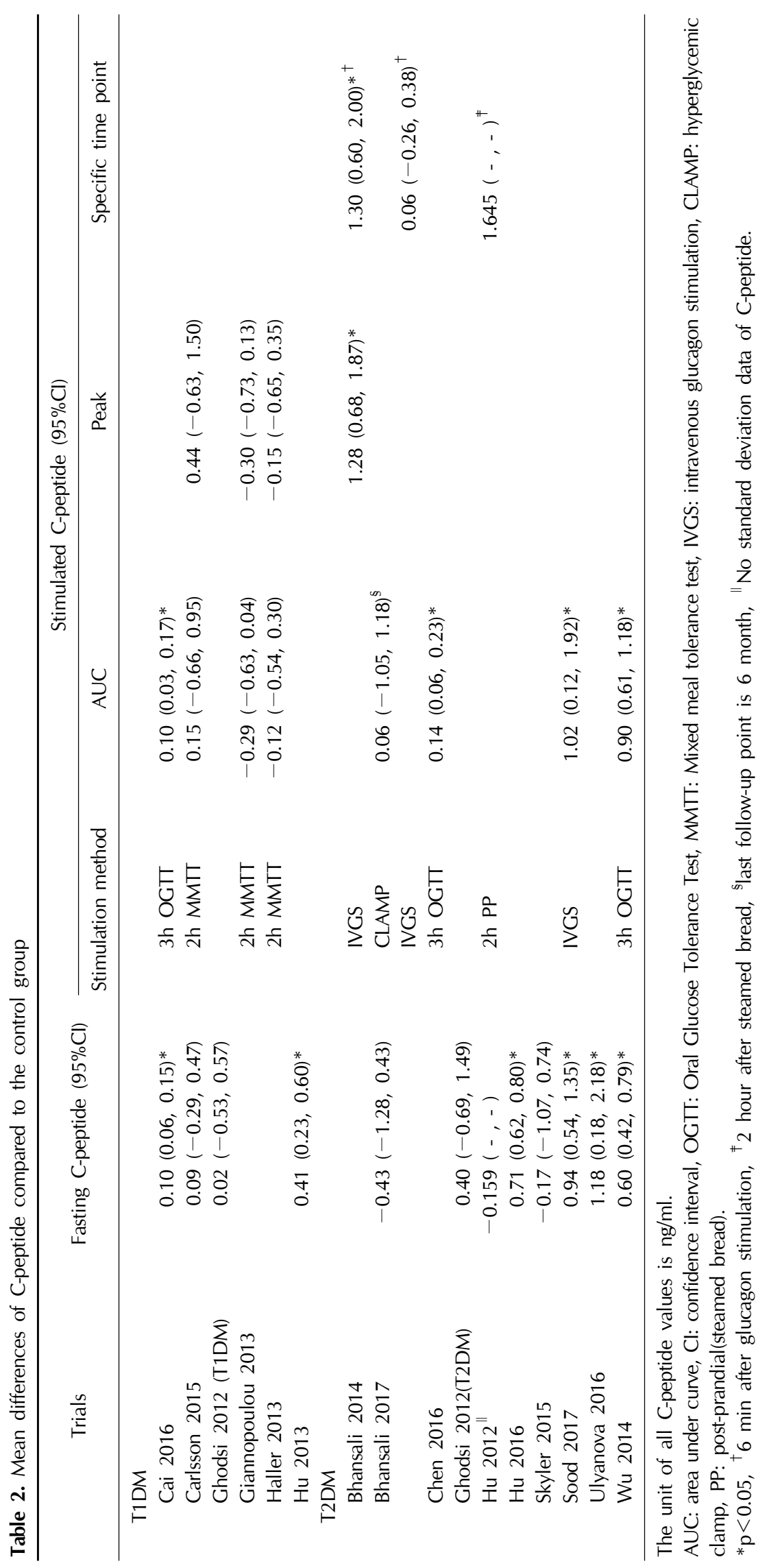


logical and clinical heterogeneity. Since the subgroup and meta-regression analyses required more than 10 studies, we analyzed after combining T1DM and T2DM studies. To investigate the clinical heterogeneity, we analyzed the differences according to DM type, cell origin, cell type, and route of administration. When it comes to explore the methodological heterogeneity, we analyzed only the differences in treatment effects according to the study design. For fasting C-peptide, stimulated C-peptide, HbAlc, and required exogenous insulin dose, changes from the baseline to the end of study follow-up points were meta-analyzed and mean differences were calculated.

\section{Results}

\section{Characteristics of the included trials}

From the selected final 15 articles, total of 16 trials were analyzed and six were T1DM and 10 were T2DM trials
(Table 1). A total of 610 patients (153 T1DM, 457 T2DM) underwent stem cell therapy or conventional therapy. Stem cell therapy group was total of 332 patients, and control group without stem cell therapy was total of 278 patients. The smallest sample size was 12 , the largest sample size was 118 , and the median of the sample size was 28.5. Stem cells used were either autologous or allogeneic stem cells depending on their origin. Stem cells were administered by intravenous (IV) injection or by catheterization to target arteries such as pancreatic duodenal or pancreatic artery. 3 cases had the follow up period over 24 months, 9 cases of 12 months, and 4 cases under 6 months.

There were 13 RCTs and 3 non-RCTs.

\section{Quality assessment}

The RCT quality was assessed by Cochrane collaboration tool for assessing risk of bias and all 13 trials were

\section{(a)}

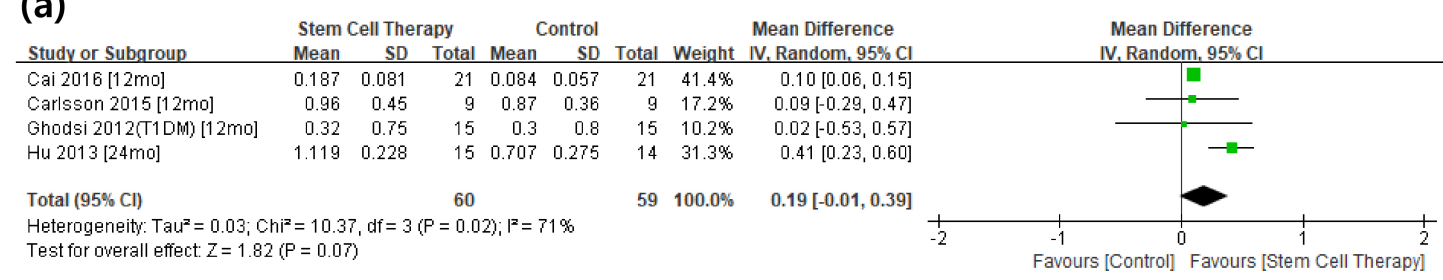

\section{(b)}

\begin{tabular}{lrrrrr} 
& \multicolumn{3}{c}{ Stem Cell Therapy } & \multicolumn{2}{c}{ Control } \\
Study or Subgroup & Mean & SD & Total & Mean & SD \\
\hline Cai 2016 [12mo] & 0.227 & 0.135 & 21 & 0.128 & 0.075 \\
Carlsson 2015 [12mo] & 2.479 & 0.993 & 9 & 2.331 & 0.736 \\
Giannopoulou 2013 [12mo] & 0.199 & 0.224 & 7 & 0.494 & 0.463 \\
Haller 2013 [12mo] & 0.3 & 0.403 & 10 & 0.42 & 0.381 \\
& & & & & \\
Total $(95 \% \mathrm{Cl})$ & & \multicolumn{4}{c}{47} \\
Heterogeneity: Tau $=0.03 ;$ Chi $^{2}=6.14, \mathrm{df}=3(\mathrm{P}=0.10) ; \mathrm{I}^{2}=51 \%$ \\
Test for overall effect: $Z=0.31(\mathrm{P}=0.75)$
\end{tabular}

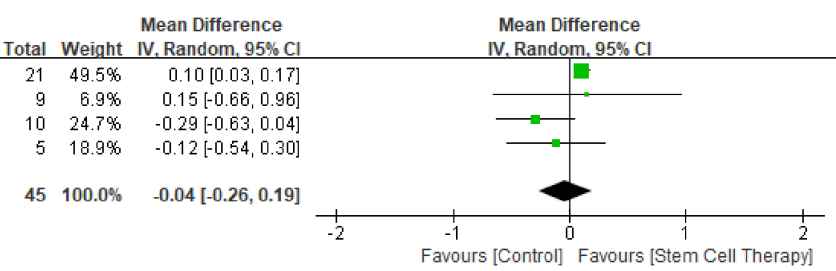

\section{(c)}

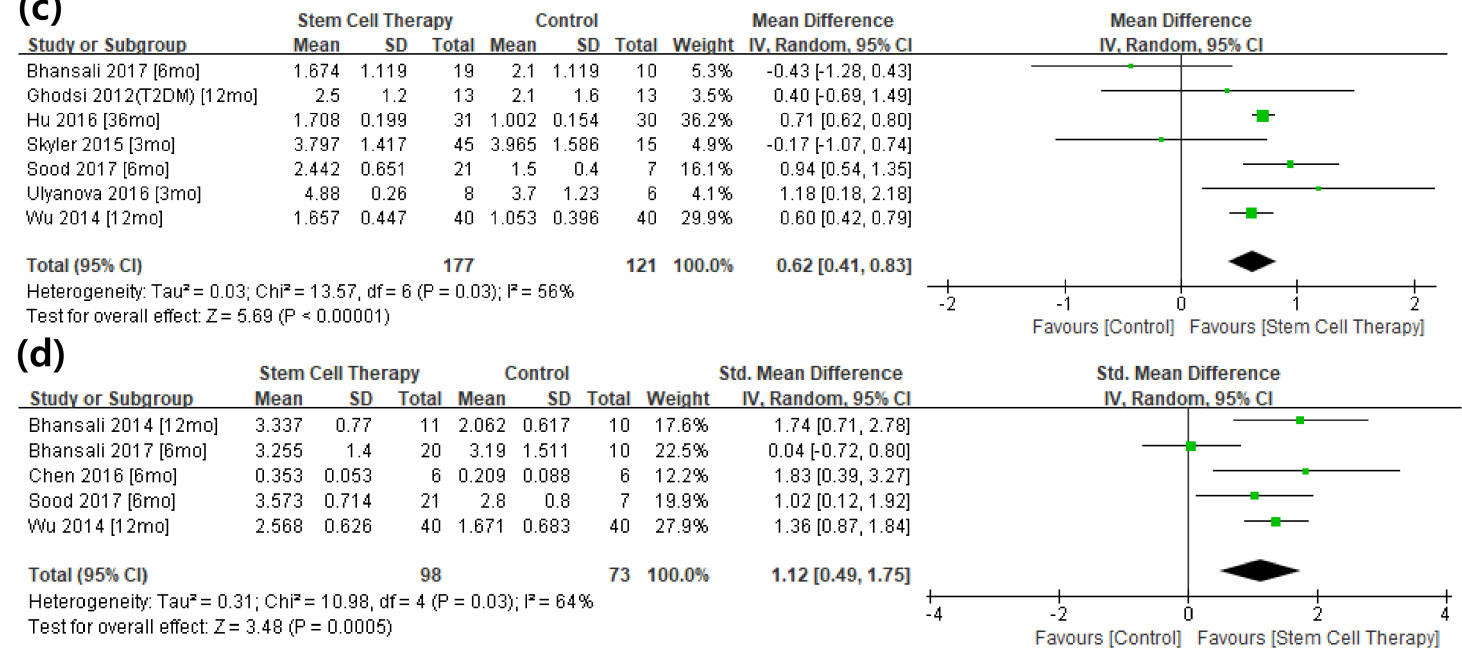

Fig. 2. Forest plots of effect sizes at end of study follow-up points in C-peptide. (a) Fasting C-peptide of T1DM, (b) Stimulated C-peptide of T1DM, (c) Fasting C-peptide of T2DM, (d) Stimulated C-peptide of T2DM. 
high risk of bias (Table 1). There was a possibility of bias in terms of appropriateness of randomization, whether it was blinded in measurement of outcomes, or report of selective results (Supplementary Table S1).

No trial was assessed as low risk of bias in the quality assessment of NRCT with ROBINS-I. Two were moderate risk of bias, and one was serious risk of bias (Table 1). Trial with serious risk of bias did not referred to dietary and exercise behaviors as confounding variables, and the definition of intervention group was not clear (Supplementary Table S2).

Various C-peptide measurements methods used for each study were presented in Table 2. Fasting C-peptide was measured in 4 trials of T1DM and 8 trials of T2DM, and we could not extract standard deviation information in 1 out of 8 T2DM cases. Stimulated C-peptide was measured in 4 trials of T1DM and in 6 trials of T2DM, and we could not extract standard deviation information in 1 out of 6 T2DM cases. We contacted the authors to gain information of the standard deviation. However, it was not possible to obtain the data; we excluded those trials from the meta-analysis. 5 Types of stimulus methods were used to measure Stimulated C-peptide, oral glucose tolerance test (OGTT), mixed meal tolerance test (MMTT), IV glucagon stimulation (IVGS), Hyperglycemic clamp (CLAMP), and steamed bread post prandial (PP). Three methods used to measure the stimulated C-peptides include measuring the area under the curve (AUC), the value at specific time points, and the peak value.

Treatment effects of stem cell therapy (SCT) were different between T1DM and T2DM. In T1DM, there was no significant difference between the intervention group and the control group in fasting C-peptide and stimulated C-peptide at the time of follow-up (MD: 0.19, 95\% CI: -0.01 to $0.39 \mathrm{p}=0.07$ and $\mathrm{MD}:-0.04,95 \% \mathrm{CI}:-0.26$ to 0.19 $\mathrm{p}=0.75$, respectively $)$ with significant heterogeneity $\left(I^{2}=\right.$ $71 \%$ and $I^{2}=51 \%$, respectively). In T2DM, fasting C-peptide and stimulated C-peptide were significantly increased in the group receiving stem cell therapy compared to the control group (MD: $0.62,95 \%$ CI: 0.41 to $0.83 \mathrm{p}<0.001$ and MD: $1.12,95 \%$ CI: 0.49 to $1.75 \mathrm{p}<0.001$, respectively) with significant heterogeneity $\left(I^{2}=56 \%\right.$ and $I^{2}=64 \%$, respectively) (Fig. 2).

The effect of SCT on T1DM and T2DM was different in the alterations from the baseline to the end of study follow-up points in C-peptide, HbAlc, and daily required exogenous insulin dose (Fig. 3). In T1DM, there was no significant difference between SCT group and control group in fasting C-peptide, stimulated C-peptide, and exogenous insulin requirements. HbAlC only showed favor- (a)

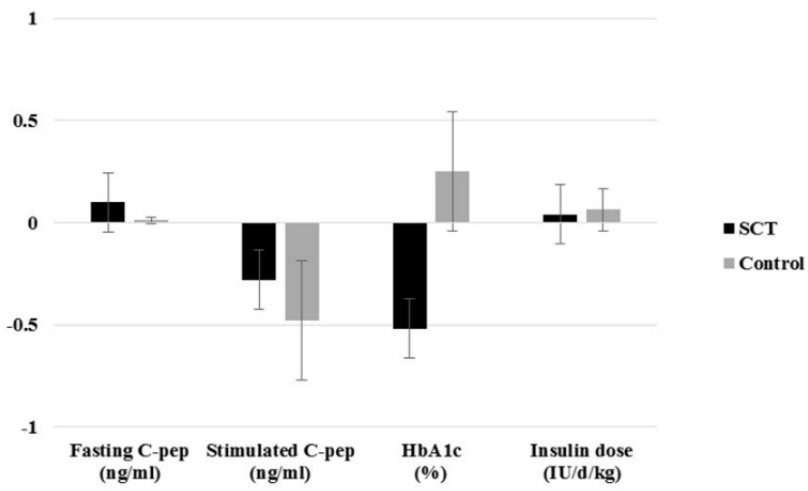

(b)

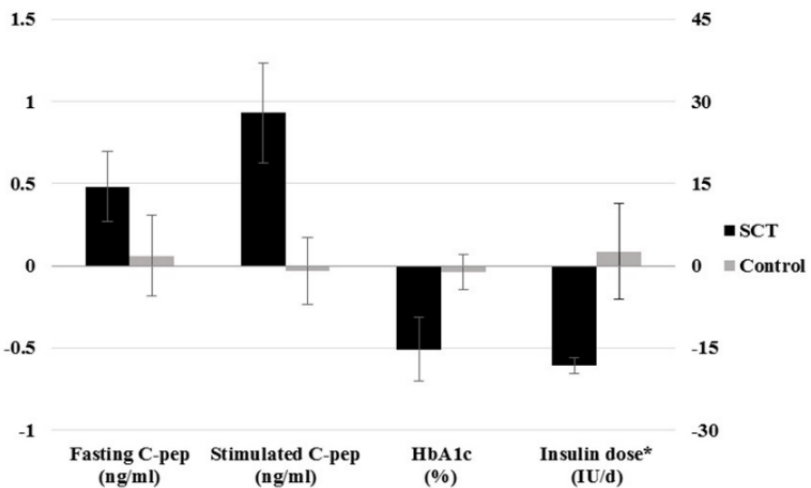

Fig. 3. The alterations from the baseline at the end of study follow-up points in C-peptide, $\mathrm{HbA} 1 \mathrm{c}$ and daily required exogenous insulin dose. (a) T1DM, (b) T2DM.

able stem cell. On the other hand, T2DM showed a favorable SCT pattern in all of stimulated C-peptide, exogenous insulin requirement, and $\mathrm{HbAlC}$, except fasting C-peptide changes.

\section{Discussion}

There are several limitations in the interpretation of $\beta$ -cell function. Since maintaining the near normal glycemic control in diabetes treatment is the standard of care, HbAlc is usually kept at 7 or less, and thus evaluating the effect of stem cells on $\beta$-cell function by only HbAlC changes is limited (12). The required exogenous insulin dose also indirectly and imperfectly reflects the $\beta$-cell function and can be greatly influenced by patient compliance, exercise, and insulin sensitivity (12).

C-peptide is a surrogate marker that represents endogenous insulin secretion. Methods for assessing C-peptide responsiveness include the use of serum C-peptide levels in the fasting state and the stimulation method. There are many factors that affect insulin secretion in $\beta$-cells. The 
key regulator factor is blood glucose level, and other factors include $\beta$-cell function, $\beta$-cell secretory capacity, insulin resistance, insulin sensitivity, glucotoxicity, exogenous insulin therapy, exercise and nutrition, etc. (31). Especially fasting blood glucose (FBG) level can be greatly influenced by other factors rather than the therapeutic effect, so it is of limited value to evaluate the $\beta$-cell function using fasting C-peptide levels which is regulated by FBG. There was a report that a large dinner meal of previous day elevated the "fasting" glucose level in the next morning despite sufficient post-fasting measurements (32). Fasting C-peptide levels are used primarily to reflect insulin resistance in patients who do not have insulin therapy. Fasting C-peptide levels are low because $\beta$-cell stimulation is low in insulin therapy patients, and it should be considered integratively together with the glucose level (33). Stimulated C-peptide rather than fasting $\mathrm{C}$-peptide is recommended to measure the therapeutic efficacy of $\beta$-cell function (12-14).

When interpreted centering on stimulated C-peptide, there was no difference between stem cell therapy group and control group in T1DM patients, and in T2DM patients, favoring stem cell therapy is shown, thus the use of stem cells seems to improve $\beta$-cell function only in patients with T2DM (Fig. 2).

To determine whether locally injected stem cell treatment has enhanced $\beta$-cell function in diabetic patients, it is necessary to consider the exogenous insulin dose, HBA1C concentration, fasting C-peptide, and stimulated C-peptide change patterns simultaneously. In T2DM patients, there were significant favoring patterns for stem cell therapies in the changes of stimulated C-peptide, HbAlc, and exogenous insulin dose versus baseline, and fasting C-peptide also showed favoring pattern though it was not significant statistically (Fig. 3). Use of stem cells in patients with T2DM improved $\beta$-cell function.

Four major mechanisms for C-peptide responsiveness after stem cell therapy could be considered. First, injected stem cells could directly differentiate into pancreatic $\beta$ cells. In vitro, it has been reported that embryonic stem cells (ESCs) differentiated into functional $\beta$-cells, and in rodents it has been reported that stem cells derived from hematopoietic organs differentiated into functional pancreatic endocrine cells (34). The second is the generation of new $\beta$-cells by recruiting progenitor cells with potency to differentiate into $\beta$-cells by the paracrine effect. It was reported when diabetic mouse was intravenously injected with enhanced green fluorescent protein (eGFP) labeled adult stem cells, its hyperglycemia normalized and $\beta$ cell mass recovered fully, but there was no evidence of insulin secreting eGFP positive donor cells and only increased cell cycle activity of remaining (eGFP negative) $\beta$ cells were shown (35). The third is to protect the remaining $\beta$-cells and facilitate repair and proliferation by reducing pro-inflammatory cytokines and increasing anti-inflammatory cytokines. After 'Stem cell educator' therapy in T1DM and T2DM patients which is to reinject lymphocytes after educating them into human cord blood-derived multipotent stem cells in vitro, number of regulatory $\mathrm{T}$ cells (Tregs) increased, the cytokine balance between $\mathrm{T}$ helper (Th) cells recovered, and C-peptide increased $(36,37)$. The fourth is to inhibit autoimmunity and hence prevent further destruction of residual $\beta$ cells and slow or reverse the progression of DM. There was a report that by non-myeloablative autologous hematopoietic stem cell transplantation in patients with T1DM, anti-glutamic acid decarboxylase (GAD) antibody titers were significantly reduced compared to baseline, and HbAlc and exogenous insulin dose also showed favoring reactions (38).

In T1DM, there was no significant difference between control group and stem cell therapy group in changes of three indicators except for HbAlc (Fig. 3). Considering the T1DM pathologic mechanism of selective insulin-producing $\beta$-cell destruction by autoimmunity, stem cell therapy did not delay or reverse T1DM progression because it does not significantly reduce autoimmunity or restore the inflammatory cytokine balance of the population.

Previous meta-analyses have shown that stem cell therapy is effective in both T1DM and T2DM patients. (15-17). However, there were several limitations with the previous meta-analysis. No trial with a control group was used in the analysis of C-peptide in patients with T1DM and included conventional BMT trials and analysis without distinction between fasting C-peptide and stimulated C-peptide.

As for the limitation of this study, first, the current meta-analysis showed high heterogeneity. The sub-group analysis did not explain the heterogeneity both clinical factors, including DM type, cell origin, cell type, and route of administration and methodological characteristic (study design) (Supplementary Table S3). None of the variables was related to influential factors in meta-regression analysis (Supplementary Table S4). There might be the variability in true effect sizes due to the factors that have not yet been identified. If the heterogeneity is substantially high, the observed direction and magnitude of effect should be interpreted with caution. However, in addition to the results of stimulated C-peptide, fasting Cpeptide, HbAlc, and daily insulin requirement changes also showed moving toward improving diabetes together. It 
is suggestive of that observed directions of effect of stem cell therapy may improve $\beta$ cell function in T2DM. Second, the quality of the included studies was low using both the Cochrane ROB and ROBINS-I. The RCTs were high risk of bias and NRCTs were evaluated as moderate or serious risk of bias. Further verification through a rigorously designed study is warranted.

\section{Acknowledgments}

This research was supported by a grant (18172MFDS182) from the Ministry of Food \& Drug Safety in 2018. The Ministry of Food \& Drug Safety had no further role in areas of study design, collection, Ms. Songui Choi conducted Chinese translation into Korean of the reference written in Chinese.

\section{Potential Conflict of Interest}

The authors have no conflicting financial interest.

\section{Author Contributions}

$\mathrm{GH}, \mathrm{HH}$, and $\mathrm{HJ}$ participated in eligibility screening, and data extraction. $\mathrm{HH}$ and $\mathrm{HJ}$ conducted protocol preparation, data analysis and interpretation. GH attended writing the manuscript; HWY participated in the scientific concept, eligibility screen, data extraction, quality assessment data analysis, analysis and interpretation of data, protocol preparation, scientific guidance, and critical review of the manuscript. $\mathrm{HY}, \mathrm{HK}$, and IO participated in data verification and critical review of the manuscript. NK participated in the systematic data search as a medical librarian. All authors read and approved the final manuscript.

\section{Supplementary Materials}

Supplementary data including four table can be found with this article online at http://pdf.medrang.co.kr/paper/ pdf/IJSC/IJSC-12-s18076.pdf.

\section{References}

1. Effect of intensive therapy on residual beta-cell function in patients with type 1 diabetes in the diabetes control and complications trial. A randomized, controlled trial. The Diabetes Control and Complications Trial Research Group. Ann Intern Med 1998;128:517-523

2. Kahn SE. Clinical review 135: the importance of beta-cell failure in the development and progression of type 2 diabetes. J Clin Endocrinol Metab 2001;86:4047-4058

3. U.K. prospective diabetes study 16. Overview of 6 years' therapy of type II diabetes: a progressive disease. U.K. Prospective Diabetes Study Group. Diabetes 1995;44:12491258

4. Levy J, Atkinson AB, Bell PM, McCance DR, Hadden DR. Beta-cell deterioration determines the onset and rate of progression of secondary dietary failure in type 2 diabetes mellitus: the 10-year follow-up of the Belfast Diet Study. Diabet Med 1998;15:290-296

5. Bagust A, Beale S. Deteriorating beta-cell function in type 2 diabetes: a long-term model. QJM 2003;96:281-288

6. Voltarelli JC, Couri CE, Stracieri AB, Oliveira MC, Moraes DA, Pieroni F, Coutinho M, Malmegrim KC, Foss-Freitas MC, Simões BP, Foss MC, Squiers E, Burt RK. Autologous nonmyeloablative hematopoietic stem cell transplantation in newly diagnosed type 1 diabetes mellitus. JAMA 2007;297: 1568-1576

7. Couri CE, de Oliveira MC, Simões BP. Risks, benefits, and therapeutic potential of hematopoietic stem cell transplantation for autoimmune diabetes. Curr Diab Rep 2012;12: 604-611

8. Snarski E, Milczarczyk A, Torosian T, Paluszewska M, Urbanowska E, Król M, Boguradzki P, Jedynasty K, Franek E, Wiktor-Jedrzejczak W. Independence of exogenous insulin following immunoablation and stem cell reconstitution in newly diagnosed diabetes type I. Bone Marrow Transplant 2011;46:562-566

9. Estrada EJ, Valacchi F, Nicora E, Brieva S, Esteve C, Echevarria L, Froud T, Bernetti K, Cayetano SM, Velazquez $\mathrm{O}$, Alejandro R, Ricordi C. Combined treatment of intrapancreatic autologous bone marrow stem cells and hyperbaric oxygen in type 2 diabetes mellitus. Cell Transplant 2008;17:1295-1304

10. Bhansali S, Dutta P, Kumar V, Yadav MK, Jain A, Mudaliar S, Bhansali S, Sharma RR, Jha V, Marwaha N, Khandelwal $\mathrm{N}$, Srinivasan A, Sachdeva N, Hawkins M, Bhansali A. Efficacy of autologous bone marrow-derived mesenchymal stem cell and mononuclear cell transplantation in type 2 diabetes mellitus: a randomized, placebo-controlled comparative study. Stem Cells Dev 2017;26:471-481

11. Ghodsi M, Heshmat R, Amoli M, Keshtkar AA, Arjmand B, Aghayan H, Hosseini P, Sharifi AM, Larijani B. The effect of fetal liver-derived cell suspension allotransplantation on patients with diabetes: first year of follow-up. Acta Med Iran 2012;50:541-546

12. Cernea S, Raz I, Herold KC, Hirshberg B, Roep BO, Schatz DA, Fleming GA, Pozzilli P, Little R, Schloot NC, Leslie RD, Skyler JS, Palmer JP; D-Cure Workshop. Challenges in developing endpoints for type 1 diabetes intervention studies. Diabetes Metab Res Rev 2009;25:694-704

13. Greenbaum CJ, Harrison LC; Immunology of Diabetes Society. Guidelines for intervention trials in subjects with newly diagnosed type 1 diabetes. Diabetes 2003;52:1059-1065

14. Palmer JP, Fleming GA, Greenbaum CJ, Herold KC, Jansa LD, Kolb H, Lachin JM, Polonsky KS, Pozzilli P, Skyler JS, Steffes MW. C-peptide is the appropriate outcome measure for type 1 diabetes clinical trials to preserve beta-cell func- 
tion: report of an ADA workshop, 21-22 October 2001. Diabetes 2004;53:250-264

15. Wang ZX, Cao JX, Li D, Zhang XY, Liu JL, Li JL, Wang M, Liu Y, Xu BL, Wang HB. Clinical efficacy of autologous stem cell transplantation for the treatment of patients with type 2 diabetes mellitus: a meta-analysis. Cytotherapy 2015; 17:956-968

16. El-Badawy A, El-Badri N. clinical efficacy of stem cell therapy for diabetes mellitus: a meta-analysis. PLoS One 2016; 11:e0151938

17. Cao JX, Zhao YQ, Ding GC, Li JL, Liu YS, Wang $M, X u$ BL, Liu JL, Wang ZX. Evaluation of the clinical efficacy of stem cell transplantation in patients with type 1 diabetes mellitus. Int J Clin Exp Med 2016;9:19034-19051

18. Ulyanova O, Taubaldieva Z, Tuganbekova S, Saparbayev S, Kim N, Trimova R, Kozina L, Shaimardanova G. Leptin level in patients with type 2 diabetes mellitus after fetal pancreatic stem cell transplant. Exp Clin Transplant 2016;14 (Suppl 3):45-47

19. Chen $\mathrm{P}$, Huang $\mathrm{Q}, \mathrm{Xu} X J$, Shao ZL, Huang LH, Yang XZ, Guo W, Li CM, Chen C. [The effect of liraglutide in combination with human umbilical cord mesenchymal stem cells treatment on glucose metabolism and $\beta$ cell function in type 2 diabetes mellitus]. Chin J Int Med 2016;55:349-354. Chinese

20. Wu Z, Cai J, Chen J, Huang L, Wu W, Luo F, Wu C, Liao L, Tan J. Autologous bone marrow mononuclear cell infusion and hyperbaric oxygen therapy in type 2 diabetes mellitus: an open-label, randomized controlled clinical trial. Cytotherapy 2014;16:258-265

21. Sood V, Bhansali A, Mittal BR, Singh B, Marwaha N, Jain A, Khandelwal N. Autologous bone marrow derived stem cell therapy in patients with type 2 diabetes mellitus - defining adequate administration methods. World J Diabetes 2017;8:381-389

22. Skyler JS, Fonseca VA, Segal KR, Rosenstock J; MSBDM003 Investigators. Allogeneic mesenchymal precursor cells in type 2 diabetes: a randomized, placebo-controlled, dose-escalation safety and tolerability pilot study. Diabetes Care 2015;38:1742-1749

23. $\mathrm{Hu}$ J, Yu X, Wang Z, Wang F, Wang L, Gao H, Chen Y, Zhao W, Jia Z, Yan S, Wang Y. Long term effects of the implantation of Wharton's jelly-derived mesenchymal stem cells from the umbilical cord for newly-onset type 1 diabetes mellitus. Endocr J 2013;60:347-357

24. Hu J, Wang Y, Gong H, Yu C, Guo C, Wang F, Yan S, Xu H. Long term effect and safety of Wharton's jelly-derived mesenchymal stem cells on type 2 diabetes. Exp Ther Med 2016;12:1857-1866

25. Haller MJ, Wasserfall CH, Hulme MA, Cintron M, Brusko TM, McGrail KM, Wingard JR, Theriaque DW, Shuster JJ, Ferguson RJ, Kozuch M, Clare-Salzler M, Atkinson MA, Schatz DA. Autologous umbilical cord blood infusion followed by oral docosahexaenoic acid and vitamin D supplementation for C-peptide preservation in children with Type 1 diabetes. Biol Blood Marrow Transplant 2013;19:1126-1129
26. Carlsson PO, Schwarcz E, Korsgren O, Le Blanc K. Preserved $\beta$-cell function in type 1 diabetes by mesenchymal stromal cells. Diabetes 2015;64:587-592

27. Cai J, Wu Z, Xu X, Liao L, Chen J, Huang L, Wu W, Luo F, Wu C, Pugliese A, Pileggi A, Ricordi C, Tan J. Umbilical cord mesenchymal stromal cell with autologous bone marrow cell transplantation in established type 1 diabetes: a pilot randomized controlled open-label clinical study to assess safety and impact on insulin secretion. diabetes care. 2016;39:149-157

28. Bhansali A, Asokumar P, Walia R, Bhansali S, Gupta V, Jain A, Sachdeva N, Sharma RR, Marwaha N, Khandelwal N. Efficacy and safety of autologous bone marrow-derived stem cell transplantation in patients with type 2 diabetes mellitus: a randomized placebo-controlled study. Cell Transplant 2014;23:1075-1085

29. Giannopoulou EZ, Puff R, Beyerlein A, von Luettichau I, Boerschmann H, Schatz D, Atkinson M, Haller MJ, Egger D, Burdach S, Ziegler AG. Effect of a single autologous cord blood infusion on beta-cell and immune function in children with new onset type 1 diabetes: a non-randomized, controlled trial. Pediatr Diabetes 2014;15:100-109

30. Hu J, Li C, Wang L, Zhang X, Zhang M, Gao H, Yu X, Wang F, Zhao W, Yan S, Wang Y. Long term effects of the implantation of autologous bone marrow mononuclear cells for type 2 diabetes mellitus. Endocr J 2012;59:1031-1039

31. Hill NR, Levy JC, Matthews DR. Expansion of the homeostasis model assessment of $\beta$-cell function and insulin resistance to enable clinical trial outcome modeling through the interactive adjustment of physiology and treatment effects: iHOMA2. Diabetes Care 2013;36:2324-2330

32. King AB. Misled by the morning "fasting" plasma glucose. J Diabetes Sci Technol 2015;9:1342-1345

33. Jones AG, Hattersley AT. The clinical utility of C-peptide measurement in the care of patients with diabetes. Diabet Med 2013;30:803-817

34. Hussain MA, Theise ND. Stem-cell therapy for diabetes mellitus. Lancet 2004;364:203-205

35. Huss R, Xiangwei X, Heimberg H. [Adult stem cells regenerate the endocrine pankreas and normalize hyperglycaemia and insulin production in diabetic mice]. Verh Dtsch Ges Pathol 2005;89:184-190. German

36. Zhao Y, Jiang Z, Zhao T, Ye M, Hu C, Yin Z, Li H, Zhang Y, Diao Y, Li Y, Chen Y, Sun X, Fisk MB, Skidgel R, Holterman M, Prabhakar B, Mazzone T. Reversal of type 1 diabetes via islet $\beta$ cell regeneration following immune modulation by cord blood-derived multipotent stem cells. BMC Med 2012;10:3

37. Zhao Y, Jiang Z, Zhao T, Ye M, Hu C, Zhou H, Yin Z, Chen Y, Zhang Y, Wang S, Shen J, Thaker H, Jain S, Li Y, Diao Y, Chen Y, Sun X, Fisk MB, Li H. Targeting insulin resistance in type 2 diabetes via immune modulation of cord blood-derived multipotent stem cells (CB-SCs) in stem cell educator therapy: phase I/II clinical trial. BMC Med 2013; $11: 160$

38. Cantú-Rodríguez OG, Lavalle-Gonzalez F, Herrera-Rojas 
MA, Gutiérrez-Aguirre $\mathrm{CH}$, Mancías-Guerra C, Jaime-Pérez JC, Gonzalez-Llano O, Zapata-Garrido A, Villarreal-Perez JZ, Gomez-Almaguer D. Autologus hematopoietic stem cell transplant in type 1 diabetes mellitus in a nonmyeloablative and outpatient setting. Blood 2014;124:1191 